\title{
Can Costal Chondrosarcoma Be Cured?
}

\author{
Lok Yuh Ing*
}

Hospital Pulau Pinang, Pulau Pinang, Malaysia

DOI: $10.36347 /$ sjmcr.2020.v08i04.006

| Received: 27.03.2020 | Accepted: 03.04.2020 | Published: 05.04.2020

*Corresponding author: Lok Yuh Ing

\section{Abstract}

Primary chest wall tumours are rare tumours which account for $<5 \%$ of thoracic malignancies. $50-80 \%$ primary chest wall tumours are malignant tumours. Thoracic chondrosarcoma is the commonest malignant primary chest wall tumour which occurred in $30 \%$ of all malignant primary chest wall tumours. We report a case of a 62-year-old gentleman presented with left chest wall mass associated with pain. CT scan showed left 9th rib mass with intraperitoneal extension. Histopathological examination showed costal conventional chondrosarcoma, grade 2 . Patient underwent tumour resection with a safe margin of $4 \mathrm{~cm}$, and chest wall reconstruction. Subsequently, he had radiotherapy due to close surgical margins. After 6 months' follow-up, patient's ECOG is 0 and no evidence of recurrence.

Keywords: Costal chondrosarcoma, chest wall tumour.

Copyright @ 2020: This is an open-access article distributed under the terms of the Creative Commons Attribution license which permits unrestricted use, distribution, and reproduction in any medium for non-commercial use (NonCommercial, or CC-BY-NC) provided the original author and source are credited.

\section{INTRODUCTION}

Primary chest wall tumours are rare tumours which account for $<5 \%$ of thoracic malignancies [1]. $50-80 \%$ primary chest wall tumours are malignant tumours [2]. Thoracic chondrosarcoma is the commonest malignant primary chest wall tumour which occurred in $30 \%$ of all malignant primary chest wall tumours [3]. Chondrosarcoma is a malignant tumour with cartilaginous differentiation, contains foci of tumour-induced or endochondral ossification with definitive diagnosis based on histology. CT imaging is required for diagnosis, for assessment of tumour invasion to nearby structure or metastasis, and for operative planning. Surgical excision with wide safe margin is the definite treatment since costal chondrosarcoma is relatively insensitive to chemotherapy and radiotherapy [4].

\section{Case Presentation}

A 62-year old gentleman with underlying hypertension and dyslipidemia presented with left chest wall mass which increased in size progressively over 6 months' period and associated with pain [Figure 1]. He had no constitutional symptom, no underlying bone disease, and no history of chemotherapy or radiotherapy. Chest X-ray showed vague left chest wall mass (red circle area) without lung abnormality [Figure 2]. CT thorax and abdomen showed left 9th rib mass with intraperitoneal extension but no organ invasion
[Figure 3]. Fine needle aspiration showed chondrosarcoma.

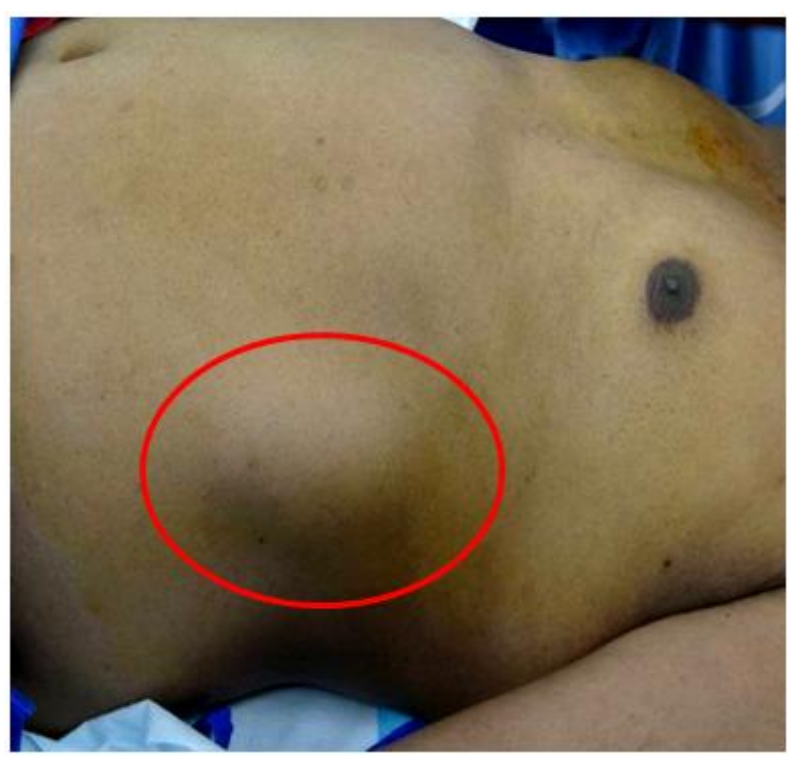

Fig-1: Left chest wall mass (red circle area) 


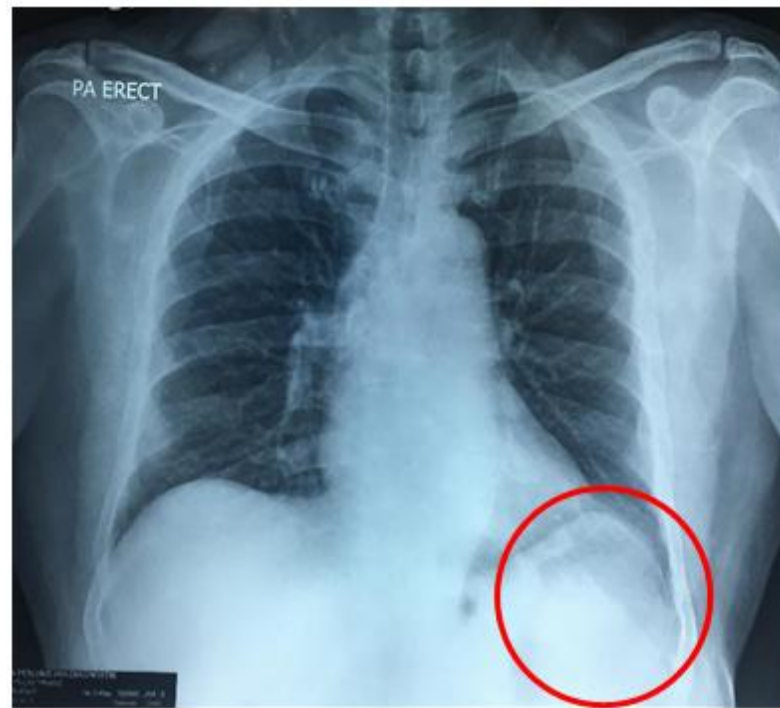

Fig-2: Chest X-ray showed vague left chest wall mass (red circle area) without lung abnormality

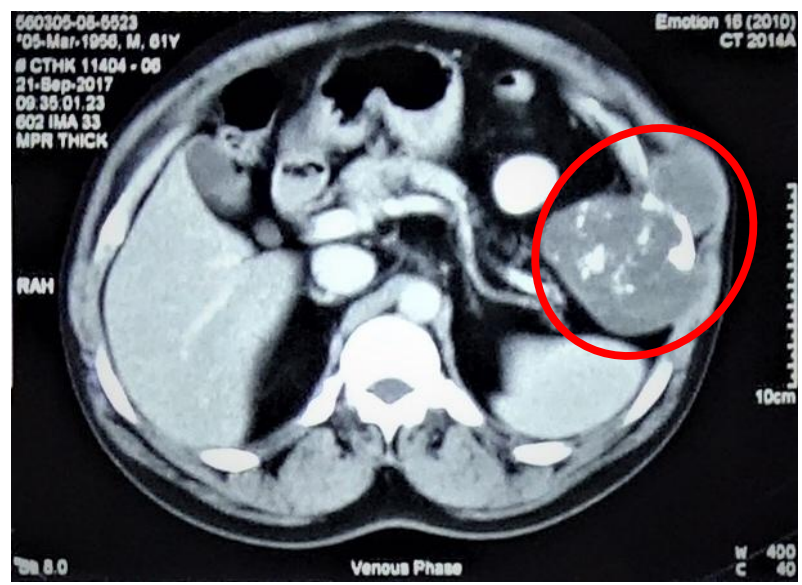

Fig-3: CT thorax and abdomen showed left 9th rib mass with intraperitoneal extension (red circle area) but no organ invasion

After case discussion in multi-disciplinary meeting which includes cardiothoracic surgeons, plastic surgeons and orthopedic surgeons, patient was arranged for surgery. Intra-operative findings showed left $9^{\text {th }}$ rib mass measured $8 \times 10 \mathrm{~cm}$ externally with involvement of overlying muscle, and intraperitoneal extension measured $10 \times 15 \mathrm{~cm}$ with diaphragm involvement measured $5 \times 7 \mathrm{~cm}$ [Figure 4]. Otherwise, no intraabdominal organs invasion noted. Hence, enbloc resection of diaphragm, rib mass, overlying muscle with a safe margin of $4 \mathrm{~cm}$ were performed, followed by repair of diaphragm (direct suture of diaphragm to chest wall) and chest wall reconstruction with rectus abdominis muscle flap to cover $12 \times 12 \mathrm{~cm}$ chest wall defect resulting from tumour resection [Figure 6].

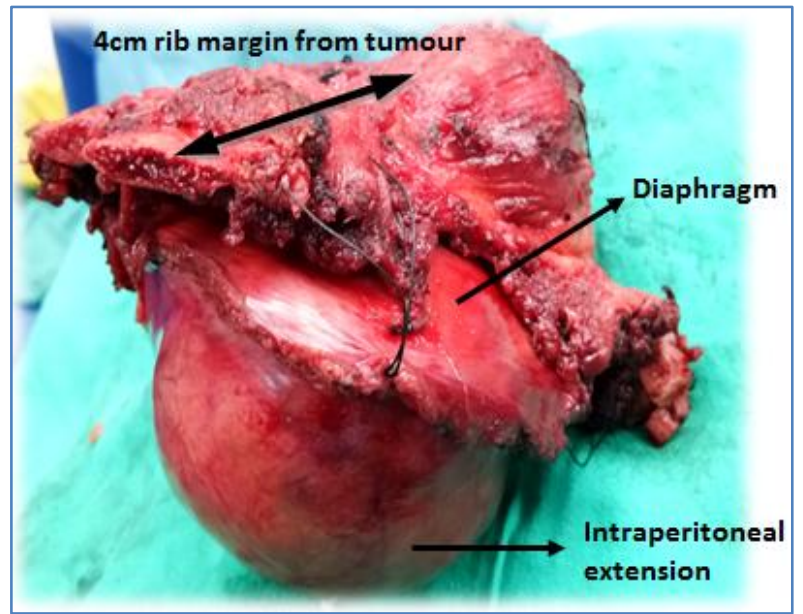

Fig-4: Left 9th rib mass measured $8 \times 10 \mathrm{~cm}$ externally with involvement of overlying muscle, and intraperitoneal extension measured $10 \times 15 \mathrm{~cm}$ with diaphragm involvement measured $5 \times 7 \mathrm{~cm}$. Surgical resection with safe margin of $4 \mathrm{~cm}$

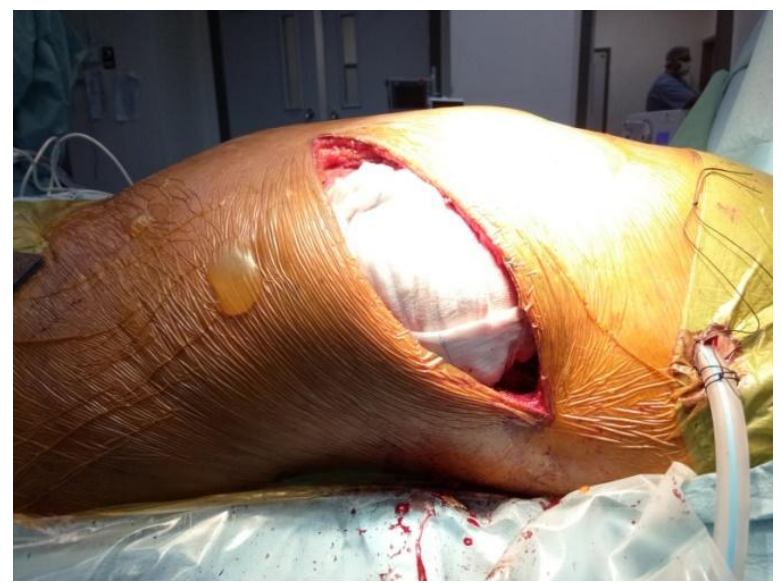

Fig-5: $12 \times 12 \mathrm{~cm}$ chest wall defect after rib tumour resection

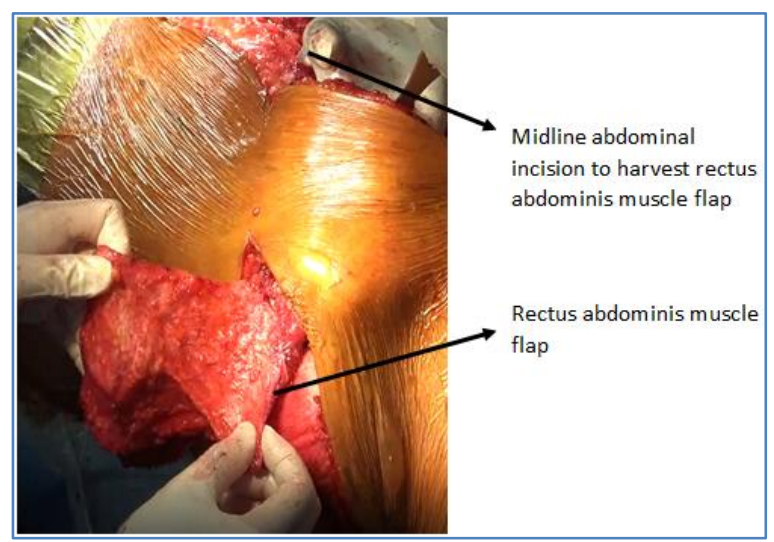

Fig-6: Chest wall reconstruction by using rectus abdominis muscle flap

Histopathological examination showed conventional chondrosarcoma, grade 2, Stage IIb (pT2N0M0). Subsequently, he had radiotherapy due to close surgical margins. After 6 months' follow-up, patient's ECOG is 0 and no evidence of recurrence. 


\section{DISCUSSION}

Primary chest wall tumours are rare tumours which account for $<5 \%$ of thoracic malignancies [1]. $50-80 \%$ primary chest wall tumours are malignant tumours [2]. Thoracic chondrosarcoma is the commonest malignant primary chest wall tumour which occurred in $30 \%$ of all malignant primary chest wall tumours [3]. Chondrosarcoma is a malignant tumour with cartilaginous differentiation, contains foci of tumour-induced or endochondral ossification. It commonly arises de novo bone (primary or central) within the medullary cavity of but can result from malignant transformation of the cartilage cap of a preexisting benign cartilaginous tumour such as enchondroma or osteochondroma (secondary or peripheral) or can arise in patient with previous radiation [5]. Majority of the patients present with an enlarging painful anterior chest wall tumour. It occurs predominantly in males and usually presents above 50 years old.

Every patient with chest wall mass will have chest X-ray as initial investigation. It may occasionally reveal the features of costal chondrosarcoma include "popcorn" calcification, endosteal scalloping and lytic lesion [6]. However, the chest X-ray of this patient did not show any of these features. Apart from X-ray, contrasted CT scan of thorax and upper abdomen should be performed in every patient with chest wall mass for diagnosis since it is more sensitive than X-ray to reveal the salient feature of chondrosarcoma which is a well-defined mass with foci of chondroid matrix calcification or "popcorn" calcification [7]. Besides, CT scan is important to detect the extent of invasion, pulmonary metastasis and for operative planning. Rarely, MRI is required for costal chondrosarcoma with mediastinal, paravertebral, or thoracic outlet involvement to define vascular or neural involvement. PET scan is sometimes performed to differentiate benign cartilaginous tumours from chondrosarcoma and to rule out extrapulmonary metastases. Histopathology is the gold standard of diagnosis either through percutaneous biopsy or open biopsy [8]. In view of possible tumour seeding along the biopsy tract, the site of biopsy should be decided with consideration given for eventual removal at definitive resection later[9].

First line therapy of costal chondrosarcoma is surgical resection in view of costal chondrosarcoma is relatively resistant to chemotherapy or radiotherapy [10]. Since costal chondrosarcoma has high potential for locoregional invasion and recurrence after treatment, wide resection should be performed by removing rib en bloc with a safety margin of at least $4 \mathrm{~cm}$ and, two intercostal spaces above and below. If overlying skin, subcutaneous tissues, muscle and internal organ are involved, they should be resected en bloc with an appropriate margin. If uninvolved by tumour, they may be spared. In view of large chest wall defect after surgical resection, chest wall reconstruction is crucial to maintain chest stability, respiratory functions and protect internal organs. These reconstruction techniques include pedicled skin and muscle flaps, free skin grafts, autologous bone transplants or prosthetic material depending on the extent and localization of the defect. In our case, chest wall reconstruction was performed by using rectus abdominis muscle flap for inferior anterolateral chest wall defect.

Costal chondrosarcoma is a slow growing tumour with low fraction of dividing cells. Hence, chondrosarcoma is relatively resistant to radiotherapy or chemotherapy. Radiotherapy can be considered in situations where resection is incomplete or resection is not feasible. While chemotherapy should be considered in patients with mesenchymal chondrosarcoma or in the case of metastatic disease as palliative chemotherapy [11].

Costal chondrosarcoma has high possibility of recurrence despite of treatment especially in patient with high tumour grade or inadequate margins at initial resection. Hence, lifelong surveillance is mandatory. Surveillance consists of physical examination and thoracic imaging with either postero-anterior/lateral radiograph or CT scan every 3-6 months for the first 5years and annually thereafter for a minimum of 10 years.

\section{CONCLUSION}

Wide surgical excision is the first line therapy for chondrosarcoma and chest wall reconstruction is often needed to maintain chest stability, respiratory functions and protect internal organs. Due to the possibility of local and systemic recurrence, patient should undergo routine lifelong surveillance after surgery.

\section{Lists of abbreviations used}

ECOG - Eastern Cooperative Oncology Group performance status

CT - Computed tomography

MRI - Magnetic resonance imaging

PET - Positron emission tomography

\section{ACKNOWLEDGEMENTS}

Written consent was obtained from the patient for publication of study.

\section{REFERENCES}

1. D'ddario G, Früh M, Reck M, Baumann $P$, Klepetko W, Felip E. Metastatic non-small-cell lung cancer: ESMO Clinical Practice Guidelines for diagnosis, treatment and follow-up. Ann Oncol. 2010;21:v116-v119. doi: 10.1093/annonc/mdq189.

2. Primary chest wall tumors: factors affecting survival. King RM, Pairolero PC, Trastek VF, 
Piehler JM, Payne WS, Bernatz PE. Ann Thorac Surg. 1986 Jun; 41(6):597-601.

3. McAfee MK, Pairolero PC, Bergstralh EJ, Piehler JM, Unni KK, McLeod RA, Bernatz PE, Payne WS. Chondrosarcoma of the chest wall: factors affecting survival. The Annals of thoracic surgery. 1985 Dec 1;40(6):535-41.

4. Malignant bone tumors. Gibbs CP Jr, Weber K, Scarborough MT. Instr Course Lect. 2002; 51():413-28.

5. Giuffrida AY, Burgueno JE, Koniaris LG, Gutierrez JC, Duncan R, Scully SP. Chondrosarcoma in the United States (1973 to 2003): an analysis of 2890 cases from the SEER database. JBJS. 2009 May 1;91(5):1063-72.

6. Roche CJ, O'Keeffe DP, Lee WK, Duddalwar VA, Torreggiani WC, Curtis JM. Selections from the buffet of food signs in radiology. Radiographics. 2002 Nov;22(6):1369-84.
7. Murphey MD, Walker EA. From the archives of the AFIP: imaging of primary chondrosarcoma: radiologic-pathologic correlation. Radiographics. 2003;23:1245-1278.

8. Evaluation of core needle biopsy as a substitute to open biopsy in the diagnosis of soft-tissue masses. Ray-Coquard I, Ranchère-Vince $\mathrm{D}$, Thiesse $\mathrm{P}$, Ghesquières H, Biron $\mathrm{P}$, Sunyach MP, Rivoire M, Lancry L, Méeus P, Sebban C, Blay JY. Eur J Cancer. 2003 Sep; 39(14):2021-5.

9. Lietman SA, Joyce MJ. Bone sarcomas: Overview of management, with a focus on surgical treatment considerations. Cleve Clin J Med. 2010;77(Suppl 1):S8-12.

10. Incarbone M, Pastorino U. Surgical treatment of chest wall tumors. World J Surg. 2001;25:218-30.

11. Huvos AG, Rosen G, Dabska M, Marcove RC. Mesenchymal chondrosarcoma a clinicopathologic analysis of 35 patients with emphasis on treatment. Cancer. 1983 Apr 1;51(7):1230-7. 